\title{
Age-Dependent ERP Correlates of Emotional Episodic Memory
}

\author{
Brigitta Tóth1,2*, Roland Boha1,2, Zsófia Kardos1,3, Bálint File1, Márk Molnár1,4 \\ ${ }^{1}$ Institute of Cognitive Neuroscience and Psychology, Research Centre for Natural Sciences, Hungarian \\ Academy of Sciences, Budapest, Hungary \\ ${ }^{2}$ Department of Cognitive Psychology, Institute of Psychology, Eötvös Loránd University, Budapest, Hungary \\ ${ }^{3}$ Department of Cognitive Science, Budapest University of Technology and Economics, Budapest, Hungary \\ ${ }^{4}$ Institute of Psychology, Eötvös Loránd University, Budapest, Hungary \\ Email: "toth.brigitta@ttk.mta.hu
}

Received 24 March 2016; accepted 3 June 2016; published 7 June 2016

Copyright (C) 2016 by authors and Scientific Research Publishing Inc.

This work is licensed under the Creative Commons Attribution International License (CC BY). http://creativecommons.org/licenses/by/4.0/

\section{(c) (i) Open Access}

\section{Abstract}

The effect of aging was studied on emotional word recognition processes. In an episodic memory task young (18 - 26 years, $N=44)$ and elderly ( $60-71$ years $N=47)$ adults were instructed to memorize a set of emotional words while EEG recording was performed. Memory performance was measured by a recognition test. The N400 and late positive complex (LPC) event-related potential components elicited by new and old words were analyzed. Decreased recognition accuracy and slower reaction time were found in the elderly irrespective of stimulus valence, except for correct rejection of neutral words, where the difference between age groups was not significant. The old/ new effect on the $\mathbf{N 4 0 0}$ was more robust in the young but for the LPC was more conspicuous in the elderly. The effect of valence observed for negative words was more pronounced in the young both in the earlier (N400) and later (LPC) latency ranges. The findings with respect to the old/new effect indicate prioritized processing of aversive stimuli in the young and may correspond to diminished capacity of adaptive behavior in the elderly.

\section{Keywords}

Age-Related Episodic Memory, ERPs, Late Positive Complex, N400, Emotions

\section{Introduction}

\subsection{Aging and Memory}

Both short term and long term memory processes are affected by aging shown by declining performance in various

${ }^{*}$ Corresponding author. 
tasks. Some of the most important aspects as reviewed in comprehensive volumes are summarized below. Age-related working memory (WM) decline is considered to be the consequence of increased vulnerability of cognitive control functions. Over activation phenomena found in neuroimaging studies of WM were usually interpreted as a result of compensatory mechanism (Reuter-Lorenz \& Sylvester, 2005). Decline in processing resources (limiting encoding and retrieving capacity), processing speed, and less effective inhibition of gating and selecting information probably all contribute to age-related long term memory deficit (reviewed by Park \& Gutschess, 2005). With respect to the declarative vs nondeclarative types of long term memory processes age-related deficits are more obvious in the declarative form of memory (Woodruff-Pak, 1997). Some aspects of memory functions such as familiarity based processes may remain relatively spared during the course of aging (McDaniel, Einstein, \& Jacoby, 2008).

\subsection{Memory, Emotions and Aging}

The enhancing effect of emotions on episodic memory processes including recognition memory has been known for long (LeDoux, 1996; Reuter-Lorenz \& Sylvester, 2005). The bulk of related data was obtained by using emotional pictures and faces as stimuli (for example Newsome, Dulas, \& Duarte, 2012; Schefter, Knorr, Kathmann, \& Werheid, 2012). The amygdala plays a crucially important role in the neurocognitive mechanisms of emotional memory especially regarding encoding and consolidation. Activation of the amygdala, hippocampus, and right prefrontal cortex were shown to accompany retrieval of emotional memory (reviewed by Hamann, 2001). The involvement of multiple brain regions in emotional memory was emphasized by LaBar and Cabeza (LaBar \& Cabeza, 2006) who emphasized the importance of frontotemporal areas that promote retention and retrieval of emotional memory events. The role of the amygdala was conceptualized in coordinating in the interaction of cortical and subcortical structures and neurohormonal systems (LaBar \& Cabeza, 2006).

Given the above mentioned effects of emotions and the brain regions affected by the aging process (Roalf, Pruis, Stevens, \& Janowsky, 2011), it seems reasonable to surmise that the decline of episodic memory capacity in aging (Dennis \& Peterson, 2012) depends on the valence of memoranda investigated. Better recognition performance with respect of images with positive valence was found to characterize the elderly ("positivity effect”, Mather \& Carstensen, 2005). This effect was confirmed for words as well (Leigland, Schulz, \& Janowsky, 2004). The “negativity bias” theory (Carretié, Albert, López-Martín, \& Tapia, 2009) maintains that aversive events require intensive processing but whether this aspect shows in memory performance is not clear.

\subsection{Aging and Event-Related Potential (ERP) Correlates of Memory}

Results of ERPs studies on age-related memory effects showed that it was stronger on perceptual than on semantic processes (Kuo, Liu, Ting, \& Chan, 2014). Compared to the young, it was found that the elderly use additional neural resources in a feature-based memory retrieval task, as revealed by ERP findings (Chiang et al., 2014). The ERP correlates of episodic recognition memory are often referred to as the "old/new effect” (Brandt, Nielsen, \& Holmes, 2013; Kayser et al., 2010). According to the dual-process theory of recognition memory these two processes are familiarity and recollection (Yonelinas, 2002). Familiarity is considered to correspond to an earlier latency range (300 - 500 ms) of ERPs showing more positivity for correctly recognized old items compared to new ones, seen in a frontocentral N400-like component. Recollection is assumed to be reflected by a later (400 - 800 ms) occurring parietal positive component, which is larger for correctly identified old items. The view that familiarity is preserved but recollection is compromised in the elderly relative to the young is well known but is still debated (Friedman, 2013). The old/new effect manifested in ERP changes was observed for both in the young and the old but only for emotional stimuli, not for neutral one (Newsome et al., 2012). A facilitating effect of emotional content on recognition performance was observed for words with negative valence (Inaba, Nomura, \& Ohira, 2005) but in this study the effect of aging was not investigated.

The ERP correlates of the old/new effect corresponding to word stimuli are analogous to the above. Changes in a frontocentral negative (N400) and a parietal positive (LPC) ERP component have consistently been reported corresponding to recognition memory performance. There is no general consensus, however, with respect to the effect of valence dimension on these ERP components (Citron, 2012; Kutas \& Federmeier, 2011). Furthermore, the issue how aging influences these ERP correlates of emotional word processing is even less settled. In a recent ERP study exploring age-related differences with respect to recognition memory performance in a speeded condition it was found that although ERP correlates of familiarity degrade with age it remains an important con- 
tributor to recognition memory (Scheuplein, Bridger, \& Mecklinger, 2014). In this study, however, pictures and not words were used as stimuli.

\subsection{Aims and Hypotheses}

Little is known about the neural correlates underlying age-related changes in emotional memory. Therefore, the present study examined age differences in recognition of negative, positive and neutral words on behavioral and ERP measures. In the present study it was hypothesized that 1) the old/new ERP correlates for words is decreased in the elderly especially for the LPC, 2) prioritized recognition of episodic events (word stimuli) with negative valence occurs both with respect to behavioral indices and electrophysiological correlates.

\section{Materials and Methods}

\subsection{Participants}

44 young and 47 elderly subjects without history of neurological or psychiatric disease participated. Participants using sedatives, sleeping pills or antidepressants and those with alcohol drinking habits were excluded. They signed a written consent before the experiment and received financial compensation for taking part in the study which was carried out in accordance with the Declaration of Helsinki and was approved by the Ethical Review Committee for Research in Psychology in Hungary. The young subjects were recruited by means of a university student agency. The elderly participants were selected partly from a pool of subjects who had participated in age-related studies earlier in the Institute of Cognitive Neuroscience and Psychology, Budapest and partly through newspaper advertisement. The years of education, age and gender, and IQ was take into account for matching the age groups.

The three subgroups of participants who were presented neutral, negative or positive word stimuli in both the young adult and elderly group were matched with respect to years of education and IQ (tested with the Hungarian standardized version of Wechsler Intelligence Scale) (Table 1). The assignment of participants to either subgroup representing the 3 stimulus valences was performed in a randomized way. No significant IQ differences were found between any of the groups by analysis of variance.

\subsection{Stimuli}

The word stimuli (nouns and adjectives) used in the present study were the same as used in a recent one (Molnár et al., 2013). The Hungarian translation of the Affective Norms for English Words (ANEW, Stevenson et al., 2007) was used. The validation of the Hungarian version was accomplished by asking 54 subjects (who did not take part in the later EEG-study) to rank the words using a 5-level scale with respect to arousal and valence. The negative, positive and neutral words selected to be used in the EEG study differed with respect to valence ratings as tested by one-way ANOVA with independent samples, $\mathrm{F}(2,430)=3441.7, p<0.001$ (positive vs. negative

Table 1. Biographical data (age, gender, results of IQ tests, years of education) of the participants.

\begin{tabular}{|c|c|c|c|c|c|c|}
\hline & & $\mathrm{N}$ & Age & Male [Female] & IQ & Years of education \\
\hline \multirow{3}{*}{ Young } & Neutral & 15 & $\begin{array}{c}21.21 \\
{[S D: 1.42]}\end{array}$ & $2[13]$ & $\begin{array}{c}117.86 \\
{[S D: 8.61]}\end{array}$ & $\begin{array}{c}15.13 \\
{[\mathrm{SD}: 0.52]}\end{array}$ \\
\hline & Positive & 15 & $\begin{array}{c}21.73 \\
{[\mathrm{SD}: 2.12]}\end{array}$ & $1[14]$ & $\begin{array}{c}116.73 \\
{[S D: 7.77]}\end{array}$ & $\begin{array}{c}15 \\
{[S D: 0]}\end{array}$ \\
\hline & Negative & 14 & $\begin{array}{c}21.26 \\
{[S D: 1.71]}\end{array}$ & $3[11]$ & $\begin{array}{c}120.43 \\
{[S D: 7.32]}\end{array}$ & $\begin{array}{c}15.43 \\
{[S D: 0.85]}\end{array}$ \\
\hline \multirow{3}{*}{ Elderly } & Neutral & 15 & $\begin{array}{c}63.33 \\
{[S D: 3.82]}\end{array}$ & $4[11]$ & $\begin{array}{c}120.61 \\
{[S D: 9.57]}\end{array}$ & $\begin{array}{c}14.14 \\
{[S D: 2.91]}\end{array}$ \\
\hline & Positive & 14 & $\begin{array}{c}65.28 \\
{[S D: 3.17]}\end{array}$ & $5[9]$ & $\begin{array}{c}115.64 \\
\text { [SD: } 5.95]\end{array}$ & $\begin{array}{c}13.53 \\
{[S D: 1.81]}\end{array}$ \\
\hline & Negative & 18 & $\begin{array}{c}66.72 \\
{[\mathrm{SD}: 3.25]}\end{array}$ & $4[14]$ & $\begin{array}{c}120.88 \\
{[S D: 8.56]}\end{array}$ & $\begin{array}{c}14.26 \\
{[S D: 2.56]}\end{array}$ \\
\hline
\end{tabular}


$p<0.001$, neutral vs. positive $p<0.001$, neutral vs. negative $p<0.001$ ). In case of negative and positive words there was no difference with respect to arousal.

The following aspects were considered when compiling the list of words: valence, arousal, word length, frequency (based on the Hungarian web-based norm of word-frequency, Kornai et al., 2006) and lemma [root of the word] frequency). Lemma frequency was matched across conditions. Words with 2 - 4 syllables were used and those at the extreme ends on the lemma frequency continuum were excluded from the list.

\subsection{Procedure}

An episodic memory task was used shown in Figure 1. Each trial consisted of three phases: a study, retention and a test (recognition) phase. The sequence of the events in a single block was the following: in the study phase a list of 12 words (either neutral, positive or negative) was presented for 10,000 ms followed by a blank screen shown for 7000 ms. The subjects were asked to keep in mind the list of 12 words (retention) for the upcoming recognition test. In the test phase, after a written question ("Have you seen this word before?") all 12 words used in the study phase ("old words") and 12 "new words" of the same valence category were presented for $400 \mathrm{~ms}$ one by one in a randomly mixed way. The subjects were asked to identify each word as "old" (displayed in the study phase) or "new" (not seen before), within the 2000 ms time frame signaled by the question mark by button press (right button for "old", left for "new" word). 12 such blocks were presented. Following the first 12 blocks, the whole procedure was repeated 2 additional times making up for altogether 36 blocks. The ERPs evoked by presentation of the test word stimuli were analyzed in the present study.

\subsection{Electrophysiological Data Collection}

The participants were seated in a reclining chair with their face $125 \mathrm{~cm}$ from a 19” CRT monitor. The EEG was recorded by $33 \mathrm{Ag}$-AgCl electrodes positioned according to the international 10 - 20 system (ground: FCz, reference: tip of nose). Vertical and horizontal eye movements were recorded by electrodes placed above and below the right eye and in the outer canthi. Electrode impedance was kept below $10 \mathrm{k} \Omega$. NuAmps amplifiers (filtering: DC-70 Hz, A/D rate: $1000 \mathrm{~Hz}$ ) and the Neuroscan 4.5 and Matlab R2012b softwares were used for data acquisition and analysis.

\subsection{Data Analysis}

The Statistica 9.1 software was used for the statistical analysis of the behavioral and ERP data.

\subsubsection{Behavioral Data}

Percent values of correct (appropriately recognized as old [hit] or new [correct rejection]) and incorrect (old words inappropriately recognized as new [missed], new words inappropriately recognized as old [false alarm])

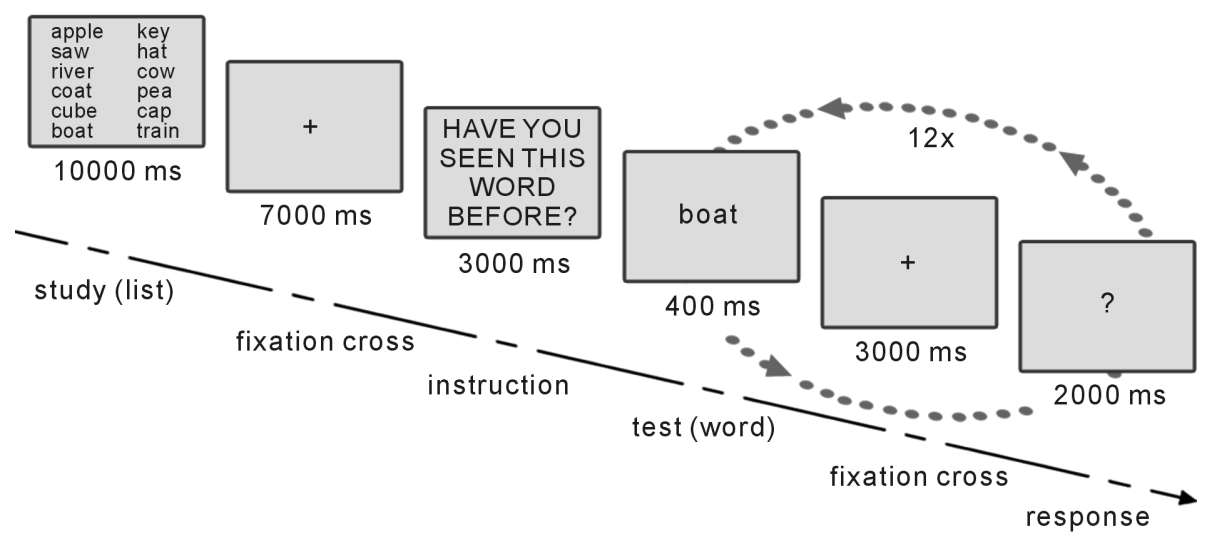

Figure 1. Scheme of the episodic memory task. The time in ms below each box refers to the time duration of each particular part of the process. The $12 \times$ in the cycle (dotted lines) indicates that the signed events were repeated 12 times in each block. A detailed explanation is given in the text. 
responses for old and new test words, and reaction times (RT) to these stimuli were measured. Repeated measures of ANOVA were performed to assess the effect of age on RT and recognition accuracy. Within subject factor was the old/new effect (old or new words) and between subject factor was the six group according to their age and valence condition category in which they participated (young neutral-negative-positive, elderly neutralnegative-positive).

\subsubsection{ERPS}

All epochs with amplitudes exceeding $\pm 50 \mu \mathrm{V}$ were excluded as a result of automatic artifact screening and visual artifact rejection. The number of epochs included in the analysis was 11,948 in the elderly and 11,852 in the young. Prior to averaging an additional filtering $(0.5-25 \mathrm{~Hz}, 24 \mathrm{~dB} /$ octave rolloff) was performed. $1600 \mathrm{~ms}$ long epochs were used for ERP averaging with a $100 \mathrm{~ms}$ baseline before stimulus delivery.

Data analysis was performed on the amplitudes of the N400 and LPC ERP components. The latency ranges of the N400 were 250 - $470 \mathrm{~ms}$ and $280-480 \mathrm{~ms}$, and those of the LPC were $510-750$ and $550-800 \mathrm{~ms}$ in the young and in the elderly group, respectively. (According to the conventional ERP component terminology, taking into account its latency, the negative wave could be designated as N2 as well. N400 is used in the present report, however, since this is the generally used term in studies dealing with word-evoked ERPs.)

The statistical analysis of EEG data consisted of two stages. First the differences of old and new words elicited ERPs were tested and in the next stage the effects of valence were analyzed on ERPs evoked only by the old words.

For the analysis of old/new effects ROIs were defined for the N400 and LPC components. Electrodes F3, F4, Fz, FC1, FC2, Cz were considered for the N400 component, whereas the ROI of LPC corresponded to the C3, C4, Cz, CP1, CP2, Pz electrodes. For the analysis of old/new effects on the ROI of N400 and on the ROI of LPC repeated measures of ANOVAs were performed separately. The within subject factors were the old/new effect (amplitude of the ERPs evoked by old and new words). The between subject factor was age (young and old).

For the analysis of valence effects on the N400 and on the LPC observed on ERPs evoked by the old words, repeated measures of ANOVAs were performed separately. To determine valence-dependent changes of the N400 and LPC, regions of interest (ROIs, corresponding to electrodes) were defined based on the amplitude distributions of these ERP components. For the N400, the four ROIs were defined by the Fp1, F3, F7 (left anterior), Fp2, F4, F8 (right anterior), Cp1, Cp5 P3, P7 (left centroparietal), and right centroparietal (Cp2, Cp6 P4, P8) electrodes. The ROI for the LPC was defined by the Cz, C3, C4, Pz, CP1, CP2 electrodes.

For the analysis of valence effects on the N400 repeated measures of ANOVAs were performed using laterality (left and right ROIs) and centrality (anterior, posterior ROIs) as within subject factors. The between subject factors were valences in the two different age groups (young neutral, young negative, young positive, and old neutral, old negative, old positive). For the analysis of valence effects on the ROI of LPC repeated measures of ANOVAs were performed using valences in the two different age groups as a between subject factors (young neutral, young negative, young positive, and old neutral, old negative, old positive).

Degrees of freedom were Greenhouse-Geisser corrected where appropriate in which cases $p$ refers to the corrected value. Post hoc analyses were performed by the Fisher test. All test variables considered had approximately normal distribution according to the results of the Kolmogorov-Smirnov test.

\section{Results}

For the sake of clarity significant $(p \leq 0.05)$ effects and tendencies $(p \leq 0.1)$ are reported.

\subsection{Behavioral Results}

Results for recognition accuracy and RT are shown in Figure 2. Recognition accuracy (hit) of old words was 81.236\% in the young and 72.076\% in the elderly (significant difference, $[\mathrm{F}(1,91)=27.017, p<0.001]$ ). Recognition accuracy for new words (correct rejection) was $91.708 \%$ in the young and $86.796 \%$ in the elderly (significant difference, $[\mathrm{F}(1,91)=11.812, p<0.001])$. For old words a significant $[\mathrm{F}(5,87)=6.008, p<0.001]$ main effect of group was found: hit accuracy was better in the young irrespective of valence. According to the post hoc tests accuracy was higher in the young than in the elderly for negative $(p=0.054)$, positive $(p=0.002)$ and neutral $(p<0.001)$ words alike. For correct rejection of new words a significant $(\mathrm{F}(5,87)=5.855, p<0.001)$ main effect of group was observed. According to the results of post hoc tests correct rejection was higher in case 

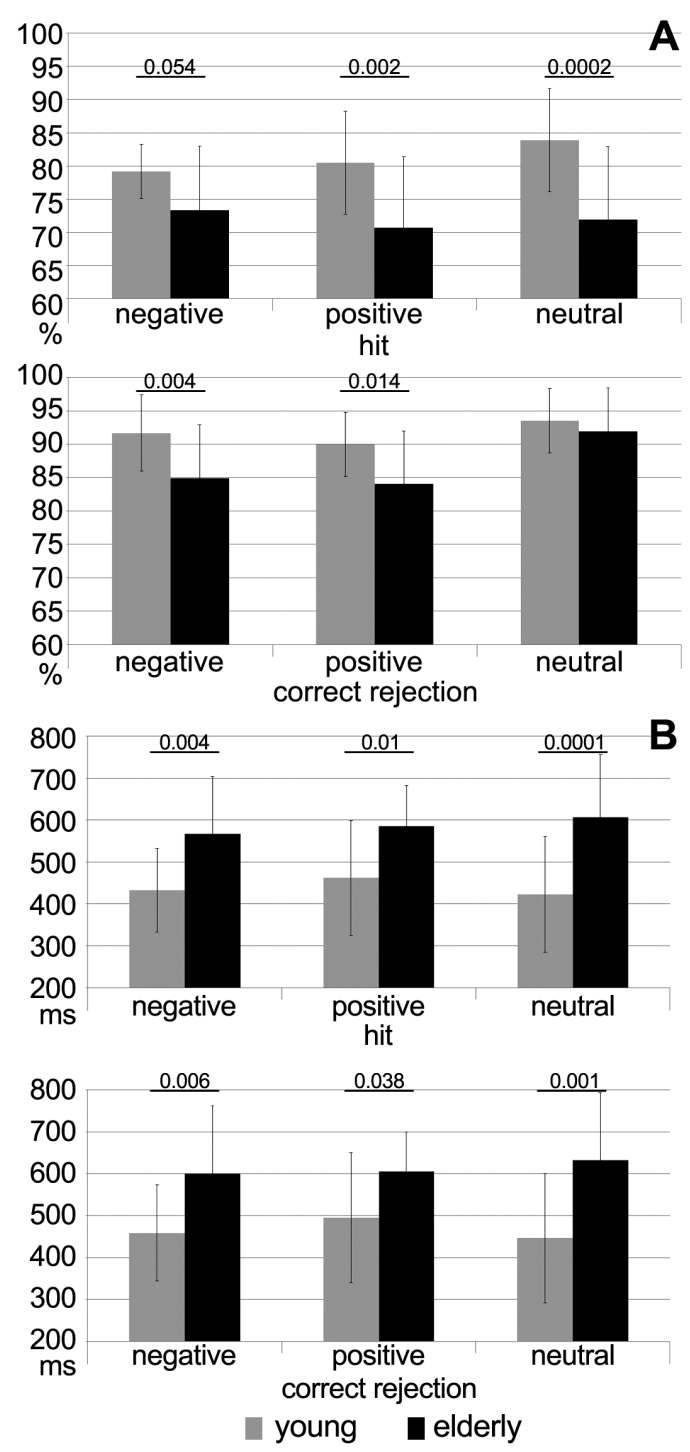

Figure 2. (A) hits and correct rejections (\% values) and (B) reaction times (in ms) for negative, positive and neutral words in the young and in the elderly. Horizontal line with numbers indicate significant differences. Vertical bars denote standard deviations.

of negative ( $p=0.004$ ), positive ( $p=0.014$ ) and neutral (no significant difference) words in the young than that observed in the elderly.

RT for hits was $439.142 \mathrm{~ms}$ in the young and $584.611 \mathrm{~ms}$ in the elderly (significant difference, $[\mathrm{F}(1,91)=$ 30.032, $p<0.001]$ ). For correct rejections RT was $466.983 \mathrm{~ms}$ in the young and $611.809 \mathrm{~ms}$ in the elderly (significant difference, $[\mathrm{F}(1,91)=24.452, p<0.001])$. A significant $[\mathrm{F}(5,87)=6.145, p=0.001]$ main effect of group was observed for hits. Post hoc analyses revealed shorter RT in the young than in the elderly for negative $(p=0.004)$, positive $(p=0.010)$ and neutral $(p<0.001)$ words alike. For correct rejections a significant $(\mathrm{F}(5,87)$ $=5.032, p<0.001$ ) main effect of group was found. According to post hoc tests RT was shorter in the young for correct rejections for negative $(p=0.006)$, positive $(p=0.038)$ and neutral $(p=0.001)$ words.

\subsection{ERPs}

Grand averages of ERPs elicited by old and new words in the two age groups recorded at $\mathrm{Cz}$ are shown in Figure 3 . The N400 component evoked by old words was markedly smaller but only in the young adults. The amplitude of 
the LPC was larger in the young and in both age groups was higher for old than for new words.

\subsubsection{Old/New Effect}

N400 ERP: The scalp distributions of the N400 ERP component evoked by correctly identified old and new words recorded in the young and in the elderly are shown in Figure 4. A conspicuous widespread old/new difference appeared in the young that extended to a large area involving bilaterally the fronto-centro-parietal regions. The N400 elicited by new words was higher (significant main effect) compared to that elicited by old items $[F(1,90)=38.74, p<0.001]$. A significant interaction was found between the old/new effect and group $[\mathrm{F}(1,90)=17.92, p<0.001]$. According to the post hoc analysis the difference the N400 amplitude evoked by old and new words was significant only in the young $(p<0.001)$.

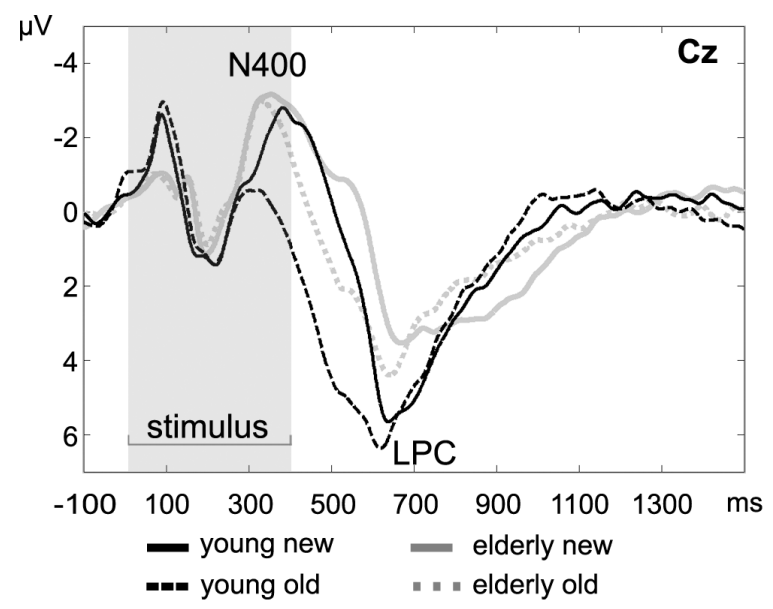

Figure 3. Grand average of ERPs corresponding to old/new categories and age groups recorded at $\mathrm{Cz}$. The shaded area indicates the presentation of the stimulus. The two ERP components (N400 and late positive complex [LPC]) analyzed in the study are labeled. The line styles refer to age (black: young subjects, grey: elderly subjects) and old/new category (solid line: new word stimuli, dotted [old subjects] or dashed [young subjects] line: old word stimuli).
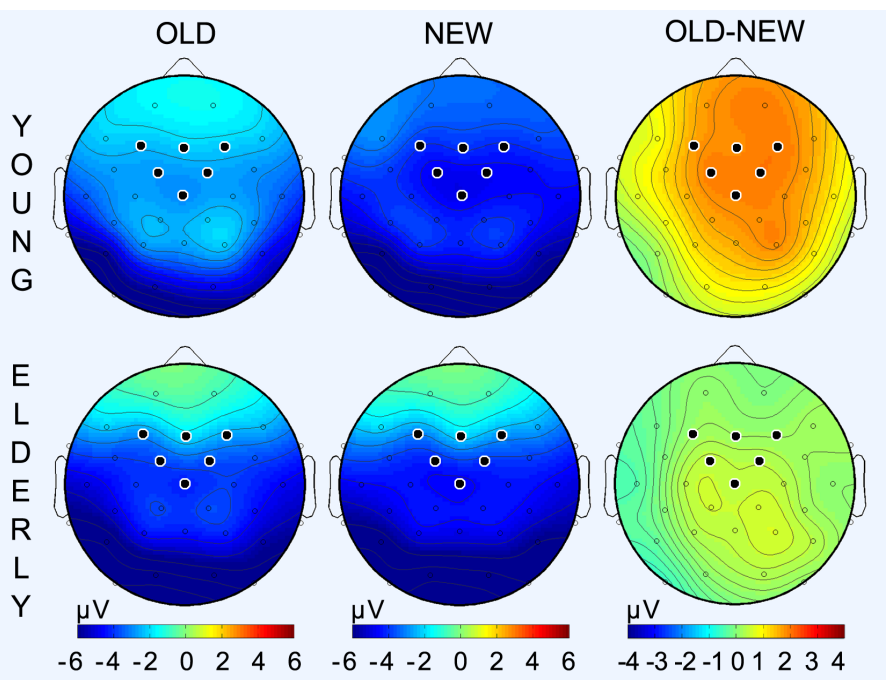

Figure 4. Scalp distribution maps of the N400 ERP component elicited by old and new words (OLD, NEW) and their difference (OLDNEW). Electrode positions used for ROI construction are shown as black dots. 
LPC ERP: The scalp distribution of the LPC component in the young and in the elderly evoked by correctly identified old and new words is shown in Figure 5. Significant $[\mathrm{F}(1,90)=19.45, p<0.001]$ group main effect was found: the amplitude of the LPC was lower in the elderly compared to the young. A significant $[\mathrm{F}(1,90)=$ 14.12, $p<0.001]$ main old/new effect was observed: LPC amplitude was higher for old than new words.

\subsubsection{Valence Effects on Old Words}

Difference maps (positive-neutral, negative-neutral) for the N4 and LPC in the two age groups are shown in Figure 6.

\section{N400 and valence:}

A significant main effect of centrality $[\mathrm{F}(1,86)=59.16, p<0.001]$, was found. The amplitude of the N400 was significantly more negative in posterior ROIs relative to the anterior ROIs. A significant main effect of laterality $[\mathrm{F}(1,86)=6.22, p=0.015]$ was found. The amplitude of the $\mathrm{N} 400$ was significantly more negative in the left ROIs relative to the right ROIs.

A significant main effect of valence groups $[F(5,86)=3.06, p=0.014]$, was found. The amplitude of the N400 evoked by old words was significantly more negative in the elderly compared to the young. Post hoc analyses revealed that in the young the N400 elicited by negative valence words differed from that evoked by positive ( $p=0.09$ tendency) and neutral $(p=0.002)$ words but no such differences were seen in the elderly. Only the negative word-evoked $\mathrm{N} 400$ were different $(p=0.024)$ in the two age groups. In the young the effect of positive words compared to neutral ones was seen as a clear bilateral parietal positivity, whereas that of negative words appeared as a robust bilateral frontal and parietal positivity (Figure 6). In contrast, in the elderly the effect of valence was subtle; no significant difference was found between neutral and positive words, and that between neutral and negative words was found only at a small fronto-temporal region in the left side. Only the negative word-evoked N4s were different ( $p=0.024$ ) in the two age groups.

A significant anterior-posterior $\mathrm{x}$ valence group interaction effect was found $[\mathrm{F}(5,86)=3.05, p=0.014]$. In the young, significant regional differences between positive and neutral words occurred at the right posterior ( $p$ $=0.067$ marginally significant) area whereas those between negative and neutral words were seen on both sides and both at the anterior and posterior regions (left anterior: $p=0.013$ ), right anterior ( $p=0.045$ ), left posterior ( $p$ $=0.045)$, right posterior $(p=0.055)$.

LPC and valence: A significant $[F(5,86)=3.28, p=0.009]$ main effect of group was observed for the LPC. Significant differences were not found with respect to valence either in the young or in the elderly. In the young a modest negativity was seen in the central area in the positive-neutral difference map while a conspicuous negative area was seen in the negative-neutral map. In the elderly obvious regional differences could hardly be seen (Figure 6).

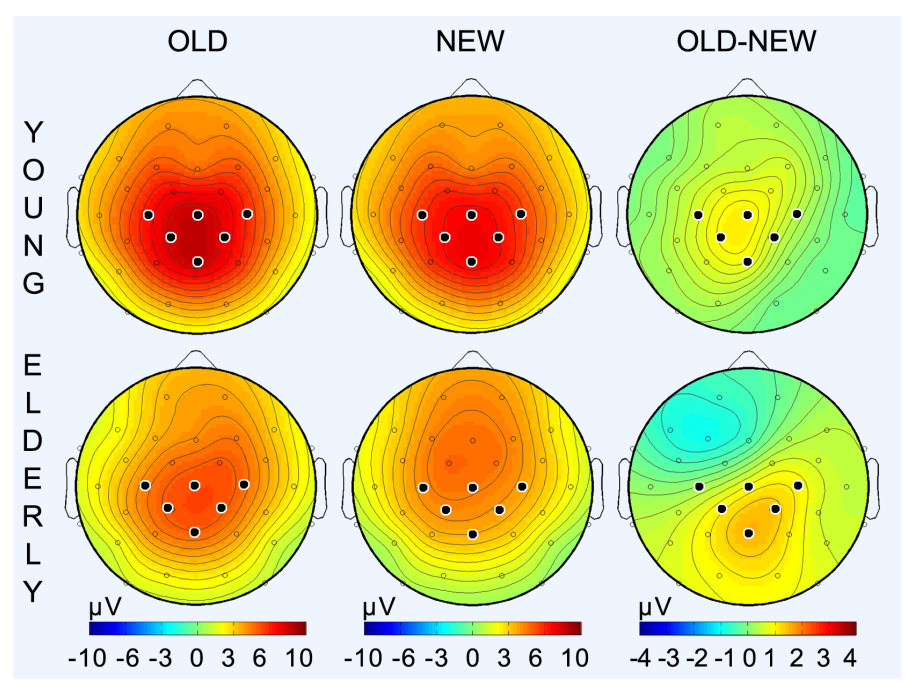

Figure 5. Scalp distribution of the LPC ERP elicited by old and new words (OLD, NEW) and their difference (OLD-NEW). Electrode positions used for ROI construction are shown as black dots. 

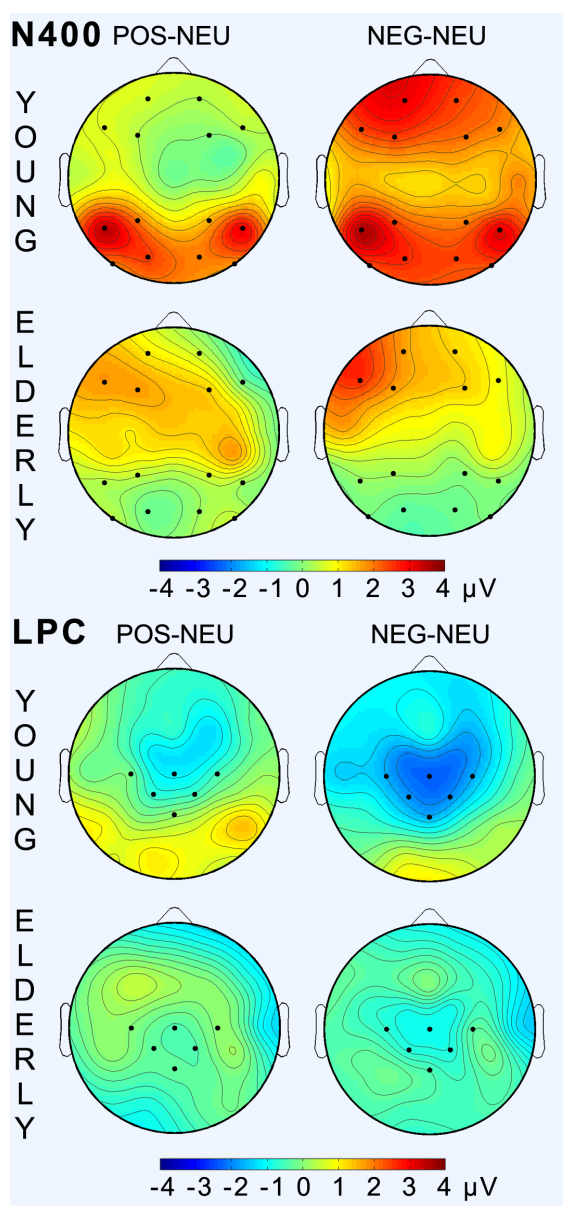

Figure 6. Scalp distribution differences of the N400 (upper part) and of the LPC (lower part) evoked by positive and neutral (POS-NEU) and negative and neutral (NEG-NEU) words in the young and in the elderly.

\section{Discussion}

\subsection{Behavioral Results}

Recognition accuracy of old words and correct rejection of new words was significantly better in the young, irrespective of valence (except for correct rejection of neutral words). These findings do not support the hypothesis (Brandt et al., 2013) concerning the accentuated processing of negative words on the behavioral level but are in line with the well-known decline of episodic memory in the elderly (Langley \& Madden, 2000). RT was significantly shorter in the young both for hits and correct rejections, irrespective of valence. It is possible that during the time available (7000 ms) for encoding, in addition to the effects of valence elaborative (semantic) encoding processes also took place which may explain high performance rates.

\subsection{N400 ERP Component}

In young adults an enhanced N400 was observed for old items compared to new ones, appearing as a large positive field in the difference map. Our findings support the well-known old/new difference effect on the N400 component, which was shown to be sensitive for item familiarity, but also for item recognition confidence and semantic priming (Friedman \& Johnson, 2000; Kutas \& Federmeier, 2011; Rugg \& Curran, 2007). This effect was markedly reduced in the elderly indicating the insufficient functioning of these mechanisms in this age group. These findings confirmed our hypothesis that the efficiency of recognition processes decline with advancing age. 
In both age groups valence-dependent changes of the N400 were apparent. No valence effect was found on the N400 by Kissler and Koessler (Kissler \& Koessler, 2011) although in their study the task was not memoryrelated. In our study, in the young the most conspicuous change was elicited by negative words involving bilaterally both the parietal and also the frontal regions, while in the elderly the significant change was confined to the left frontal area. Changes evoked by positive words were subtle, localized to the parietal area in the young and not reaching significant level in the elderly. Thus, the hypothesis that the processing of negative words would elicit more conspicuous changes in the N400 in the young was confirmed which may correspond to the prioritized processing of stimuli with negative valence. This finding is in line with the "negative bias” theory (Carretié et al., 2009) and supports our recent results (Molnár et al., 2013).

\subsection{LPC of ERPs}

In both age groups an enhanced late positive ERP component for old relative to new items was evident at parieto-central locations. Our findings support the notion that LPC indexes recognition memory processes and also that it characterizes these processes regardless of age. Age-related modulation of LPC was also observed in the present study. In the elderly the area where the old/new difference was significant was more widespread, extending to the centro-parieto-occipital regions bilaterally. Thus, our hypothesis that the old/new effect would be less conspicuous in the elderly could not be confirmed for the LPC. Age-related differences with respect to the old/new effect in this late latency range have been reported for words, usually finding a reduced or absent effect on LPC in the elderly (Guillaume et al., 2009; Walhovd et al., 2006). Other observations, however, did not support these findings (Kayser et al., 2010; Osorio, Ballesteros, Fay, \& Pouthas, 2009; Trott, Friedman, Ritter, Fabiani, \& Snodgrass, 1999; Windmann \& Kutas, 2001). In the elderly the marked old/new effect on the LPC compared to the young suggest a compensatory mechanism in the execution of the recognition task, as suggested by Tays et al. (Tays, Dywan, Capuana, \& Segalowitz, 2011). Unlike that found in the study by Kayser et al. (Kayser et al., 2010), and similarly to the findings of Osorio et al. (Osorio et al., 2009), no lateralization was observed for the distribution of the LPC. Apart from the stimuli used, probably the task itself plays also an important role from this perspective (Wolk et al., 2009).

Significant differences with respect to valence were not found either in the young or in the elderly although the most conspicuous change with respect to neutral words was elicited in the young by negative words. Late positive ERPs corresponding to hits and correct rejections were not found to be affected by valence according to Windman and Kutas (Maratos, Allan, \& Rugg, 2000; Windmann \& Kutas, 2001). Inaba et al. in a word recognition task (Inaba et al., 2005; Maratos et al., 2000) observed the largest late positive component for negative words next to positive and least to neutral ones. Citron et al. (Citron, Weekes, \& Ferstl, 2013) found larger amplitude LPC for neutral compared to emotional words, but in that study the task was not memory task related. Data pertaining to aging effects in this regard are particularly scarce. We found valence-induced changes of the LPC to be modest in the elderly. If changes of the LPC correspond to conscious recollection, this process was most obvious in the young, induced by negative words.

\subsection{Limitations}

In each age group the neutral, negative and positive word stimuli were presented in 3 different subgroups of subjects. The presentation of stimuli in 36 blocks took close to an 1 hour to accomplish. Consequently, it was not possible to collect data for each valence type in the same participant. The possibility that a "priming” effect, inducing a mood-specific state that developed during the presentation of stimuli cannot be ruled out (Federmeier, Kirson, Moreno, \& Kutas, 2001).

\section{Conclusion}

The old/new effect was robust in the N400 latency range in the young and in the LPC latency range in the elderly. This effect could hardly be seen in the elderly, which indicates the insufficient functioning of familiaritydetecting mechanisms in this age group. The markedly larger area involved in the process corresponding to the LPC in the elderly may indicate that more extended regions were recruited during recollection, possibly as a result of compensatory processes. The valence effect was found to be more conspicuous in the N400 and was subtle in the LPC but in both latencies ranges the effect of negative words was most apparent in the young. These 
findings support our hypothesis with respect to the prioritized processing of negatively biased stimuli characterizing the young. These findings also suggest that valence shifts in the aging brain are mediated by additional controlled processes such as semantic elaboration. Future studies needed to identify functional connectivity network of distributed brain regions supporting emotional functions in aging that is common or altered in young and older adults.

\section{Acknowledgements}

This research was supported by the Hungarian Research Fund OTKA 77750 and 104332 . The authors thank for the technical assistance of E. Várkonyi.

\section{Disclosure Statement}

The authors declare no actual or potential conflict of interest. All authors have reviewed the contentsof the submitted manuscript, approve of its contents and the accuracy of the data.

\section{References}

Brandt, K. R., Nielsen, M. K., \& Holmes, A. (2013). Forgetting Emotional and Neutral Words: An ERP Study. Brain Research, 1501, 21-31. http://dx.doi.org/10.1016/j.brainres.2013.01.019

Carretié, L., Albert, J., López-Martín, S., \& Tapia, M. (2009). Negative Brain: An Integrative Review on the Neural Processes Activated by Unpleasant Stimuli. International Journal of Psychophysiology, 71, 57-63. http://dx.doi.org/10.1016/j.ijpsycho.2008.07.006

Chiang, H.-S., Mudar, R. A, Spence, J. S., Pudhiyidath, A., Eroh, J., DeLaRosa, B., Hart, J., et al. (2014). Age-Related Changes in Feature-Based Object Memory Retrieval as Measured by Event-Related Potentials. Biological Psychology, 100, 106-114. http://dx.doi.org/10.1016/j.biopsycho.2014.05.010

Citron, F. M. M. (2012). Neural Correlates of Written Emotion Word Processing: A Review of Recent Electrophysiological and Hemodynamic Neuroimaging Studies. Brain and Language, 122, 211-226.

http://dx.doi.org/10.1016/j.bandl.2011.12.007

Citron, F. M. M., Weekes, B. S., \& Ferstl, E. C. (2013). Effects of Valence and Arousal on Written Word Recognition: Time Course and ERP Correlates. Neuroscience Letters, 533, 90-95. http://dx.doi.org/10.1016/j.neulet.2012.10.054

Dennis, N., \& Peterson, K. (2012). Neural Correlates Mediating Age Differences in Episodic Memories: Evidence from BOLD Contrasts and Connectivity Analyses. Psychologia, 55, 112-130. http://dx.doi.org/10.2117/psysoc.2012.112

Federmeier, K. D., Kirson, D. A., Moreno, E. M., \& Kutas, M. (2001). Effects of Transient, Mild Mood States on Semantic Memory Organization and Use: An Event-Related Potential Investigation in Humans. Neuroscience Letters, 305, $149-152$. http://dx.doi.org/10.1016/S0304-3940(01)01843-2

Friedman, D. (2013). The Cognitive Aging of Episodic Memory: A View Based on the Event-Related Brain Potential. Frontiers in Behavioral Neuroscience, 7, 111. http://dx.doi.org/10.3389/fnbeh.2013.00111

Friedman, D., \& Johnson, R. A. Y. (2000). Event-Related Potential (ERP) Studies of Memory Encoding and Retrieval : A Selective Review. Microscopy Research and Technique, 51, 6-28.

Guillaume, C., Clochon, P., Denise, P., Rauchs, G., Guillery-Girard, B., Eustache, F., \& Desgranges, B. (2009). Early Age-Related Changes in Episodic Memory Retrieval as Revealed by Event-Related Potentials. Neuroreport, 20, 191-196. http://dx.doi.org/10.1097/WNR.0b013e32831b44ca

Hamann, S. (2001). Cognitive and Neural Mechanisms of Emotional Memory. Trends in Cognitive Sciences, 5, 394-400. http://dx.doi.org/10.1016/S1364-6613(00)01707-1

Inaba, M., Nomura, M., \& Ohira, H. (2005). Neural Evidence of Effects of Emotional Valence on Word Recognition. International Journal of Psychophysiology, 57, 165-173. http://dx.doi.org/10.1016/j.ijpsycho.2005.01.002

Kayser, J., Tenke, C. E., Kroppmann, C. J., Fekri, S., Alschuler, D. M., Gates, N. A., Gil, R., Harkavy-Fiedman J. M., Jarskog L. F., \& Bruder, J. E. (2010). Current Source Density (CSD) Old/New Effects during Recognition Memory for Words and Faces in Schizophrenia and in Healthy Adults. International Journal of Psychophysiology, 75, 194-210. http://dx.doi.org/10.1016/j.ijpsycho.2009.12.001

Kissler, J., \& Koessler, S. (2011). Emotionally Positive Stimuli Facilitate Lexical Decisions—An ERP Study. Biological Psychology, 86, 254-264. http://dx.doi.org/10.1016/j.biopsycho.2010.12.006

Kuo, M. C. C., Liu, K. P. Y., Ting, K. H., \& Chan, C. C. H. (2014). Age-Related Effects on Perceptual and Semantic Encoding in Memory. Neuroscience, 261, 95-106. http://dx.doi.org/10.1016/j.neuroscience.2013.12.036 
Kutas, M., \& Federmeier, K. D. (2011). Thirty Years and Counting: Finding Meaning in the N400 Component of the Event-Related Brain Potential (ERP). Annual Review of Psychology, 62, 621-647. http://dx.doi.org/10.1146/annurev.psych.093008.131123

LaBar, K. S., \& Cabeza, R. (2006). Cognitive Neuroscience of Emotional Memory. Nature Reviews Neuroscience, 7, 54-64. http://dx.doi.org/10.1038/nrn1825

Langley, L. K., \& Madden, D. J. (2000). Functional Neuroimaging of Memory: Implications for Cognitive Aging. Microscopy Research and Technique, 51, 75-84. http://dx.doi.org/10.1002/1097-0029(20001001)51:1<75::AID-JEMT8>3.0.CO;2-6

LeDoux, J. (1996). The Emotional Brain: The Mysterious Underpinnings of Emotional Life. New York: Simon and Schuster.

Leigland, L. A., Schulz, L. E., \& Janowsky, J. S. (2004). Age Related Changes in Emotional Memory. Neurobiology of Aging, 25, 1117-2224. http://dx.doi.org/10.1016/j.neurobiolaging.2003.10.015

Maratos, E. J., Allan, K., \& Rugg, M. D. (2000). Recognition Memory for Emotionally Negative and Neutral Words: An ERP Study. Neuropsychologia, 38, 1452-1465. http://dx.doi.org/10.1016/S0028-3932(00)00061-0

Mather, M., \& Carstensen, L. L. (2005). Aging and Motivated Cognition: The Positivity Effect in Attention and Memory. Trends in Cognitive Sciences, 9, 496-502. http://dx.doi.org/10.1016/j.tics.2005.08.005

McDaniel, M. A., Einstein, G. O., \& Jacoby, L. L. (2008). New Considerations in Aging and Memory: The Glass May Be Half Full. In F. I. M. Craik, \& T. A. Salthouse (Eds.), The Handbook of Aging and Cognition (pp. 251-310). New York and Hove: Psychology Press.

Molnár, M., Tóth, B., Boha, R., Gaál, Z. A., Kardos, Z., File, B., \& Stam, C. J. (2013). Aging Effects on ERP Correlates of Emotional Word Discrimination. Clinical Neurophysiology, 124, 1986-1994. http://dx.doi.org/10.1016/j.clinph.2013.04.017

Newsome, R., Dulas, M., \& Duarte, A. (2012). The Effects of Aging on Emotion-Induced Modulations of Source Retrieval ERPs: Evidence for Valence Biases. Neuropsychologia, 50, 3370-3384. http://dx.doi.org/10.1016/j.neuropsychologia.2012.09.024

Osorio, A., Ballesteros, S., Fay, S., \& Pouthas, V. (2009). The Effect of Age on Word-Stem Cued Recall: A Behavioral and Electrophysiological Study. Brain Research, 1289, 56-68. http://dx.doi.org/10.1016/j.brainres.2009.07.013

Park, D., \& Gutschess, A. (2005). Long-Term Memory and Aging. In R. Cabeza, L. Nyberg, \& D. Park (Eds.), Cognitive neuroscience of Aging (pp. 218-245). New York: Oxford University Press.

Reuter-Lorenz, P. A., \& Sylvester, C.-Y. C. (2005). The Cognitive Neuroscience of Working Memory and Aging. In R. Cabeza, L. Nyberg, \& D. Park (Eds.), Cognitive Neuroscience of Aging (pp. 186-217). New York: Oxford University Press.

Roalf, D. R., Pruis, T. A., Stevens, A. A., \& Janowsky, J. S. (2011). More Is Less: Emotion Induced Prefrontal Cortex Activity Habituates in Aging. Neurobiology of Aging, 32, 1634-1650. http://dx.doi.org/10.1016/j.neurobiolaging.2009.10.007

Rugg, M. D., \& Curran, T. (2007). Event-Related Potentials and Recognition Memory. Trends in Cognitive Sciences, 11, 251-257. http://dx.doi.org/10.1016/j.tics.2007.04.004

Schefter, M., Knorr, S., Kathmann, N., \& Werheid, K. (2012). Age Differences on ERP Old/New Effects for Emotional and Neutral Faces. International Journal of Psychophysiology, 85, 257-269. http://dx.doi.org/10.1016/j.ijpsycho.2011.11.011

Scheuplein, A.-L., Bridger, E. K., \& Mecklinger, A. (2014). Is Faster Better? Effects of Response Deadline on ERP Correlates of Recognition Memory in Younger and Older Adults. Brain Research, 1582, 139-153. http://dx.doi.org/10.1016/j.brainres.2014.07.025

Stevenson, R., Mikels, J., \& James, T. (2007). Characterization of the Affective Norms for English Words by Discrete Emotional Categories. Behavior Research Methods, 39, 1020-1024. http://dx.doi.org/10.3758/BF03192999

Tays, W. J., Dywan, J., Capuana, L. J., \& Segalowitz, S. J. (2011). Age-Related Differences during Simple Working Memory Decisions: ERP Indices of Early Recognition and Compensation Failure. Brain Research, 1393, 62-72. http://dx.doi.org/10.1016/j.brainres.2011.04.006

Trott, C. T., Friedman, D., Ritter, W., Fabiani, M., \& Snodgrass, J. G. (1999). Episodic Priming and Memory for Temporal Source: Event-Related Potentials Reveal Age-Related Differences in Prefrontal Functioning. Psychology and Aging, 14, 390-413. http://dx.doi.org/10.1037/0882-7974.14.3.390

Walhovd, K. B., Fjell, A. M., Reinvang, I., Lundervold, A., Fischl, B., Quinn, B. T., Makris, N., \& Dale, A. M. (2006). The Functional and Structural Significance of the Frontal Shift in the Old/New ERP Effect. Brain Research, 1081, 156-170. http://dx.doi.org/10.1016/j.brainres.2006.01.076

Windmann, S., \& Kutas, M. (2001). Electrophysiological Correlates of Emotion-Induced Recognition Bias. Journal of Cognitive Neuroscience, 13, 577-592. http://dx.doi.org/10.1162/089892901750363172

Wolk, D. A., Sen, N. M., Chong, H., Riis, J. L., McGinnis, S. M., Holcomb, P. J., \& Daffner, K. R. (2009). ERP Correlates of Item Recognition Memory: Effects of Age and Performance. Brain Research, 1250, 218-231. 
http://dx.doi.org/10.1016/j.brainres.2008.11.014

Woodruff-Pak, D. S. (1997). The Neuropsychology of Aging (p. 233). Hoboken, NJ: Blackwell Publishing.

Yonelinas, A. P. (2002). The Nature of Recollection and Familiarity: A Review of 30 Years of Research. Journal of Memory and Language, 46, 441-517. http://dx.doi.org/10.1006/jmla.2002.2864 